\title{
An illustrated step-by-step protocol for investigating liverwort chromosomes
}

\author{
ARETUZA SOUSA ${ }^{1} \&$ SUSANNE S. RENNER ${ }^{1}$ \\ ${ }^{1}$ Systematic Botany and Mycology, Department of Biology, University of Munich (LMU), 80638 Munich, Germany \\ Authors for correspondence: !"aretuzasousa@gmail.com; @ https://orcid.org/0000-0003-2982-5244 \\ ="renner@lmu.de; ๑ https://orcid.org/0000-0003-3704-0703
}

\begin{abstract}
Cytogenetic studies in bryophytes have been limited by the difficulty of obtaining sufficient dividing nuclei and by the absence of modern protocols. The technical difficulties stem from the plants' small size and lack of roots and pollen mother cells, the main sources of cells in division in vascular plants. In bryophytes instead, tiny sporophytes, antheridia, or phyllid meristems must be used to obtain meiotic or mitotic chromosome spreads. We here describe the preparation of such spreads from phyllids, antheridia, and sporophytes in several species of liverworts and compare available protocols with or without prefixation treatments. We also provide illustrated step-by-step instructions. The three prefixation agents (including colchicine) that we tested failed to improve synchronization of cell divisions. Young sporophytes were the best source of diploid synchronized cells, while antheridia were the best source of haploid cells. For meiotic nuclei, a short fixation of capsule tissue at the right developmental stage with $45 \%$ acetic acid sufficed to conserve the DNA for cytological investigations, while for mitotic nuclei, fixation in 3:1 ethanol/glacial acetic acid for a longer period (4-24 h) worked well.
\end{abstract}

Key words: Liverworts, chromosome preparation, antimitotic chemicals, protocols

\section{Introduction}

The study of bryophyte chromosomes had its first flowering at the beginning of the $20^{\text {th }}$ century with the discovery of mechanisms of cell division, heterochromatin, and sex chromosomes (Van Hook, 1900; Allen, 1917; Heitz, 1928). The elongating gamete-producing structures of Marchantiales still provide some of the most favorable material for the observation of cell division (Brown and Lemmon, 1990; Brown et al., 2004), and knowing bryophyte chromosome numbers is not only of basic-biological interest but also required for purely practical reasons. This is because the de novo assembly of whole genomes requires knowing the number of expected linkage groups and hence species' chromosome numbers. The biological interest of analyzing the karyotypes of bryophytes lies especially in their unique sex chromosomes (Bull, 1978, 1983; Bachtrog et al., 2011; Sousa et al., 2021) and mechanisms of cell division. Bryophytes have distinct polar organizers that appear de novo in prophase and are involved in the organization of the spindle (Brown and Lemmon, 1990, 2004; Brown et al., 2004), and they therefore are critical for understanding the evolution of cell division. Yet, following the benchmark cytogenetic work of the $20^{\text {th }}$ century (e.g., Lorbeer, 1934; Tatuno, 1941; Berrie, 1960; Iverson, 1963; Fritsch, 1975; Newton; 1984), chromosome studies of bryophytes in recent years have become rare. Thus, during the past 25 years (1995-2020), only 15 papers have appeared on bryophyte chromosomes, most of them on liverwort chromosomes (Web of Science, search on 1 Sep. 2020). Despite this strikingly small number of studies, there were exciting discoveries and new interpretations, for example, how sporogenesis in extant liverworts helps interpret fossil evidence (Brown and Lemmon, 2011).

Reasons for the low number of scientific publications on bryophyte cytogenetics may include the small number of specialists able to determine species, the plants' small sizes, the challenge of cultivating bryophytes in the lab, and the difficulty of obtaining sufficient numbers of dividing cells for chromosome preparations. The absence of illustrated, detailed, English-language guides may also have contributed to the underrepresentation of bryophytes in modern cytogenetics. Here, we present a step-by-step protocol for the preparation of liverwort chromosomes and compare protocols with and without prefixation treatments that aim to enhance the synchronization of cell division. 


\section{Materials and Methods}

\subsection{Plant material}

Individuals of Frullania dilatata (L.) Dumort. and Radula complanata (L.) Dumort. were collected in the Truderinger Wald, a park located in the eastern part of Munich; Plagiochila asplenioides (L.) Dumort. and Conocephalum conicum (L.) were collected near the village Grub $\left(47 \mathrm{o} 55^{\circ} \mathrm{N}, 11 \mathrm{o} 46 \mathrm{E}\right)$ in the Mangfalltal. Plants were cultivated in Petri dishes in a greenhouse at the Munich botanical garden to avoid having to constantly recollect material in the field. Vouchers were deposited in the herbarium of Munich (Sousa et al., 2020).

\subsection{Fixation}

Liverwort plants were fixed either in freshly prepared 3:1 (v/v) ethanol/glacial acetic acid or in $45 \%$ acetic acid at room temperature for 4-24 h (see Results), transferred to 70\% ethanol, kept at room temperature overnight, and afterwards stored at $-20^{\circ} \mathrm{C}$ until use. We also fixed some phyllids, antheridia, and sporophytes in 8-hydroxyquinoline, colchicine, or saturated paradichlorobenzene prior to fixation in ethanol/glacial acetic acid because other studies have found these chemicals to help synchronization of cell divisions (Sone et al., 1999; Zheng and Zhu, 2008; Orzechowska et al., 2010).

\subsection{Chromosome preparation from meristems using the squash method}

Fixed material was first placed in bi-distilled water prior to the time-consuming step of dissection of apical meristems. Meristem tissue turned white (pale green/brown) after its transfer from the fixative into water, and only tissues showing such differential staining were suitable for chromosome preparations (see Figures 1A and B; red arrows and pinkstained tissue). The oven should be preheated to $37^{\circ} \mathrm{C}$ and a humid box for the incubation of slides should be prepared in parallel to the dissection step. We used circa 20 pieces of meristem per slide and kept them in a drop of water before their removal and digestion with an enzyme mix. The enzyme mix consisted of $1 \%$ cellulase (w/v; Onozuka RS, Serva), $0.4 \%$ pectolyase (w/v; Sigma), $0.4 \%$ cytohelicase (w/v; Sigma) in citric buffer, $\mathrm{pH} 4.8$, and the amount used for digestion was visually assessed based on the floating of meristems in a drop of the enzyme. We incubated slides inside of the humid box for one hour at $37^{\circ} \mathrm{C}$. Later, excess enzyme was removed with a filter paper, and a drop of freshly prepared $45 \%$ acetic acid was used to clean the material prior to its maceration in this solution. The last steps consisted of placing a coverslip on the macerated meristems and carefully pressing the coverslip down with the help of a threelayer folded filter paper to flatten the cells into a single layer. The coverslip was removed after freezing the slides with dry ice or liquid nitrogen for 2 mins. Slides were dried at room temperature for at least 10 mins before staining.
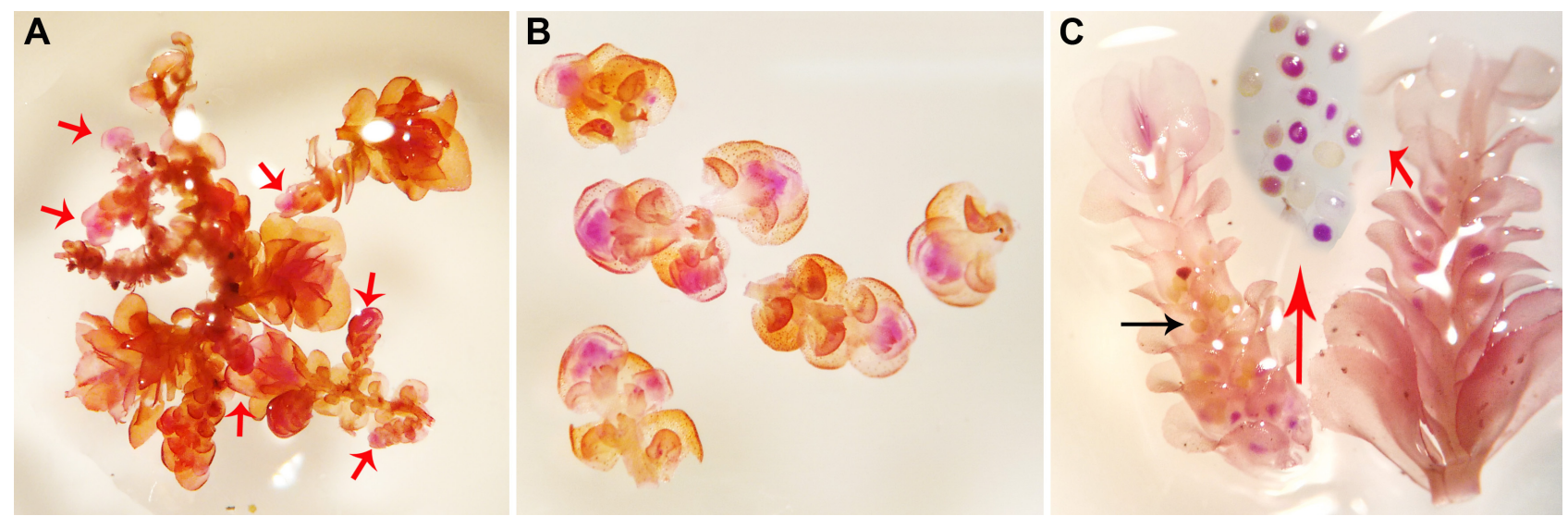

FIGURE 1. Pieces of a female individual of Frullania dilatata $(\mathbf{A}, \mathbf{B})$ and a male of Plagiochila asplenioides $(\mathbf{C})$ fixed as described in the main text and stained with the Feulgen technique, and visualized under a stereo microscope. Red arrows in (A) mark apical meristems of phyllids and young sporophytes. The black and red arrows in (C) mark antheridia that either stained with Feulgen or failed to take up this stain. (B) Pieces of plant material with meristems at higher magnification. 

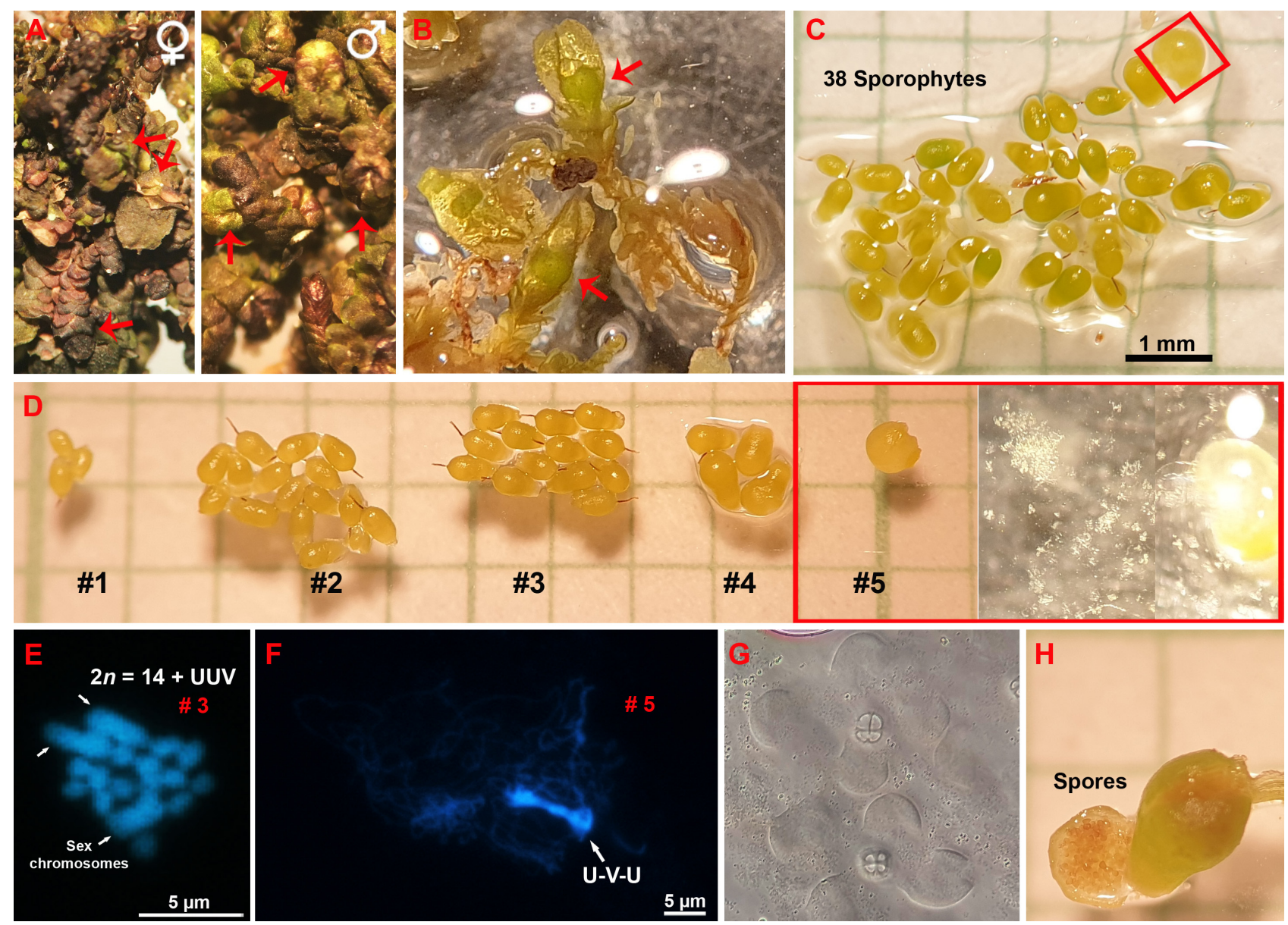

FIGURE 2. Steps used for chromosome preparations from young sporophytes. (A) Fertile male and female plants of Frullania dilatata. Red arrows indicate fertile branches. (B) Selection of young sporophytes. Red arrows indicate young sporophytes. (C) Sporophytes after removal of their perianths. (D) Developmental stages of spore capsules. Stage \#3 had the most cells in division, and only stage \#5 showed meioses. The snow-like clumps (seen under a stereoscope) are cells in meioses. (E) U and V sex chromosomes in mitosis. (F) U and V sex chromosomes in meiosis. (G). After cells are flattened under a coverslip, meiosis can be identified under a phase-contrast microscope (40x objective) by the partitioning of the sporocyte into a tetrad of spores. (H) Capsule containing mature spores.

\subsection{Chromosome preparation from meristems using the dropping method}

Fixed material was again placed in bi-distilled water $\left({ }_{\mathrm{dd}} \mathrm{H}_{2} \mathrm{O}\right)$ prior to the dissection of the apical meristem. We dissected as much of the fixed material as possible and placed all pieces into a drop of water inside a watch glass. All steps of washing occurred on ice, and all solutions were cooled. We placed the watch glass containing the plant material on a Styrofoam box with ice and washed the material twice in citric buffer, $\mathrm{pH} \mathrm{4.8,} \mathrm{each} \mathrm{time} \mathrm{for} 5 \mathrm{~min}$. We used a $1 \mathrm{ml}$ pipette to change solutions. Then, the meristems were dried with the help of a pipette and filter paper, and digested with 100-200 $\mu \mathrm{l}$ of the same enzyme mix as in 2.3. inside a humid box for $1 \mathrm{~h} 20 \mathrm{~min}$ at $37^{\circ} \mathrm{C}$. We then carefully removed the enzyme mix with 20 to $200 \mu \mathrm{l}$ pipettes and washed the cells once in citric buffer for $5 \mathrm{~min}$. After the enzymatic digestion, the meristems turned soft and sticky, and when sucked in with a pipette, they clumped in the plastic tips. Therefore, any solution had to be removed without touching the meristems. Meanwhile, the drop solution was prepared, which consisted on 1:1 methanol/glacial acetic acid placed on ice. The meristems were then washed with cold $\left(0^{\circ} \mathrm{C}\right) 100 \%$ ethanol for $3 \mathrm{~min}$. All meristems precipitated in the middle of the watch glass. The ethanol was then removed with pipettes and the plant material transferred to a 1.5-ml Eppendorf tube to which 50-100 $\mu 1$ of drop solution is added. We used forceps tips to separate the cells within the drop solution and controlled the homogeneity of the floating cells by holding the Eppendorf tube against a light source. The final solution containing the floating cells ideally should be a single-cell suspension. To apply the dropping method, a hot plate (set to $50^{\circ} \mathrm{C}$ ) covered with 
moist $\left({ }_{\mathrm{dd}} \mathrm{H}_{2} \mathrm{O}\right)$ paper is needed. We placed a slide on the moist paper and from a height of $20-40 \mathrm{~cm}$ let 8-10 $\mu$ lof the cell suspension drop onto the slide, followed by 10-20 $\mu$ l (1-2 drops) of the drop solution. We set a timer for 2 min to let the drops dry out. The ideal air humidity in the room for this work was around $50 \%$. Then, we placed each slide directly on the hot place (without the moisture paper) for about $1 \mathrm{~min}$. The slides were then ready for staining and chromosomal analyses.

\subsection{Preparation of mitotic cells from antheridia using the squash method}

Fixed plant material (see 2.2) with phyllids (leaves) containing antheridia was placed into a watch glass with ${ }_{\mathrm{dd}} \mathrm{H}_{2} \mathrm{O}$. We then dissected 5 to 10 small antheridia (Figure 1C stained in pink) and placed them in a drop of freshly prepared $45 \%$ acetic acid to perform the squash method. The cells could easily be spread using needles, and their enzymatic digestion was not necessary. Next, we added a coverslip and performed the steps described at the end of section 2.3.

\subsection{Preparation of meiotic cells from young sporophytes using the squash method}

We selected young sporophytes from fixed or fresh material (Figures 2A, B) and placed them in ${ }_{d d} \mathrm{H}_{2} \mathrm{O}$ on a slide or into a watch glass. Based on the color of the sporangium (yellow or black), it was possible to assess if spores are fully formed. The sporophytes were then dissected from the perianth (Figure 2C). Using capsule shape, we categorized developmental stages as shown in Figure 2D. Stage \#3 yielded the most mitoses (Figure 2E) and stage \#5 the most meioses (Figure $2 \mathrm{~F}$ ). We then selected sporophytes at stages $\# 3$ and $\# 5$ and added a drop of freshly prepared $45 \%$ acetic acid to break the capsules with needles so that sporocytes were released (squash method). Lastly, we added a coverslip and performed the steps described at the end of section 2.3. Before the freezing stage, sporocytes can be identified using a phase-contrast microscope as quadripolar cells (Figure 2G). Material with capsules already containing mature spores (Figure 2H) was discarded.

\section{Results}

Best plant growth was achieved under air temperatures of $10-15^{\circ} \mathrm{C}$, keeping the petri dishes in shadowed places. Plants collected during the coldest months of the year (January to March in Munich: average minimum $2.0^{\circ} \mathrm{C}$; average maximum around $10.0^{\circ} \mathrm{C}$ ) yielded a higher number of cells in division than plants cultivated at room temperature or collected during warmer months. Young sporophytes were the best source of diploid synchronized cells for chromosome preparations (Figures 2C and E), while antheridia were the best source of haploid cells (Figure 1C). The cells released after breaking the envelope of the antheridia (from the male reproductive branch) and capsules (part of the sporophyte) are easy to handle, and slides can be prepared from fresh material using a drop of $45 \%$ acetic acid without the need of enzymatic digestion. One capsule at the right stage (Figure 2D \#5) provided more than 10 cells in division per slide.

The use of apical leaf meristems or young thalli for chromosome spreads is time-consuming and requires expertise to dissect the tiny material using needles. With these tissues, the application of the dropping method provided preparations with a higher quality than the squashing method, as we verified in F. dilatata, $R$. complanata, and $C$. conicum. However, we rarely obtained more than five metaphases per slide from these tissues using one drop of cell suspension.

None of the three prefixation treatments (Materials and Methods, 2.2) helped to synchronize cells in F. dilatata; in fact, these agents increased the condensation of chromosomes and clumped them together.

\section{Discussion}

This study compared the use of different tissues (apical meristems of phyllids/thalli, antheridia, spore-forming sporophytes) and prefixation treatments in terms of their efficiency for mitotic or meiotic chromosome preparations in liverworts. The chemicals 8-hydroxyquinoline, colchicine, and saturated paradichlorobenzene appear to enhance synchronization of cell divisions in other liverworts (Sone et al., 1999: Marchantia polymorpha; Orzechowska et al., 2010; Pellia species; Zheng and Zhu, 2008: several species of liverworts), but we obtained the same number of usable metaphases with or without the use of these pre-treatments as long as the right tissue at the right stage was used. The 
best way for the preparation of chromosomes was therefore to directly fix the material, after cultivating plants for 3-12 days in a cold chamber or having collected them during cold months. The benefit of cold conditions for obtaining dividing nuclei was already reported by Lorbeer (1934), but we did not understand its importance during many months of failed attempts at obtaining sufficient dividing cells.

Another insight from this work and a related study (Sousa et al., 2021) was that it is worthwhile to benchmark the capsule stages that yield the most mitotic and meiotic nuclei (based on capsule shape and color). Using the optimal stage of development in fact was the single-most important step towards success, more important than pretreatments or precise fixation times. We hope that the color photos provided here will encourage others to attempt to study bryophyte chromosomes themselves.

Author Contributions: Conceptualization, A.S.; methodology, A.S.; validation, A.S; both authors worked on the manuscript and agreed on the final version.

Funding: The Elfriede and Franz Jakob Foundation for research at the Botanical Garden Munich supported lab consumables used for this research.

Acknowledgments: We thank Maja Orzechowska and Belén Estébanez for comments on the manuscript.

Conflicts of Interest: The authors declare no conflict of interest.

\section{References}

Allen, C.E.A. (1917) chromosome difference correlated with the sex differences in Sphaerocarpos. Science 46: 466-467. https://doi.org/10.1126/science.46.1193.466

Bachtrog, D., Kirkpatrick, M., Mank, J.E., McDaniel, S.F., Pires, J.C., Rice, W.R. \& Valenzuela, N. (2011) Are all sex chromosomes created equal? Trends in Genetics 27: 350-357.

https://doi.org/10.1016/j.tig.2011.05.005

Berrie, G.K. (1960) The chromosome number of liverworts. The British Bryological Society 3: 688-705. https://doi.org/10.1179/006813860804828963

Brown, R.C. \& Lemmon, B.E. (1990) Polar organizers mark division axis prior to preprophase band formation in mitosis of the hepatic Reboulia hemisphaerica (Bryophyta). Protoplasma 156: 74-81. https://doi.org/10.1007/BF01666508

Brown, R.C. \& Lemmon, B.E. (2004) $\gamma$-tubulin, microtubule arrays, and quadripolarity during sporogenesis in the hepatic Aneura pinguis (Metzgeriales). Journal of Plant Research 117: 371-376. https://doi.org/10.1007/s10265-004-0168-0

Brown, R.C. \& Lemmon, B.E. (2011) Spores before sporophytes: hypothesizing the origin of sporogenesis at the algal-plant transition. New Phytologist 190: 875-881. https://doi.org/10.1111/j.1469-8137.2011.03709.x

Brown, R.C., Lemmon, B.E. \& Horio, T. (2004) $\gamma$-tubulin localization changes from discrete polar organizers to anastral spindles and phragmoplasts in mitosis of Marchantia polymorpha L. Protoplasma 224: 187-193. https://doi.org/10.1007/s00709-004-0061-7

Bull, J.J. (1983) Evolution of sex determining mechanisms. The Benjamin/Cummings Publishing Company, Menlo Park, CA, USA.

Bull, J.J. (1978) Sex chromosomes in haploid dioecy: A unique contrast to Muller's theory for diploid dioecy. Amer.Naturalist 112: $235-250$ https://doi.org/10.1086/283267

Fritsch, R. (1975) Zytologische Untersuchungen an Bryophyten aus dem Harz. Hercynia Neue Folge 12: 75-79.

Heitz, E. (1928) Das Heterochromatin der Moose. I. Jahrbücher für Wissenschaftliche Botanik 69: 762-818.

Iverson, G.B. (1963) Karyotype evolution in the leafy liverwort genus Frullania. The Journal of the Hattori Botanical Laboratory 26: $119-170$

Lorbeer, G. (1934) Die Zytologie der Lebermoose mit besonderer Berücksichtigung allgemeiner Chromosomenfragen. Jahrbücher für Wissenschaftliche Botanik 80: 567-818.

Newton, M.E. (1984) The cytogenetics of bryophytes. In: Dyer, A.F. \& Duckett, J.G. (Eds.) The Experimental Biology of Bryophytes. Academic, London, pp. 65-96.

Orzechowska, M., Siwinska, D. \& Maluszynska, J. (2010) Molecular cytogenetic analyses of haploid and allopolyploid Pellia species. Journal of Bryology 32: 113-121.

https://doi.org/10.1179/037366810X12578498136075 
Sone, T., Fujisawa, M., Takenaka, M., Nakagawa, S., Yamaoka, S., Sakaida, M., Nishiyama, R., Yamato, K.T., Ohmido, N., Fukui, K., Fukuzawa, H. \& Ohyama, K. (1999) Bryophyte 5S rDNA was inserted into 35S rDNA repeat units after the divergence from higher land plants. Plant Molecular Biology 41: 679-685. https://doi.org/10.1023/A:1006398419556

Sousa, A., Bechteler, J., Temsch, E.M. \& Renner, S.S. (2020) Different from tracheophytes, liverworts commonly have mixed 35S and 5S arrays. Annals of Botany 125: 1057-1064. https://doi.org/10.1093/aob/mcaa027

Sousa, A., Schubert, V. \& Renner, S.S. (2021) Centromere organization and UU/V sex chromosome behavior in a liverwort. [Online] https://doi.org/10.1111/tpj.15150

Tatuno, S. (1941) Zytologische Untersuchungen über die Lebermoose von Japan. Journal of science of the Hiroshima University. Series B. Division 2. Botany 4: 73-187.

Van Hook, J.M. (1900) Notes on the division of the cell and nucleus in liverworts. Botanical Gazette 30: 394-399. https://doi.org/10.1086/328062

Zheng, M. \& Zhu, R-L. (2008) Liverwort anatomy and cytology. Fieldiana 47: 81-87. 